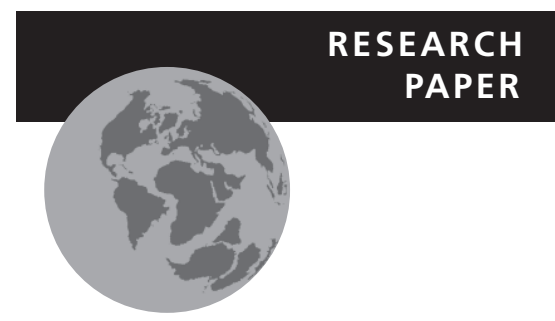

\title{
Climatic history and dispersal ability explain the relative importance of turnover and nestedness components of beta diversity
}

\author{
Ricardo Dobrovolski ${ }^{1 \star}$, Adriano S. Melo ${ }^{2}$, Fernanda A. S. Cassemiro ${ }^{3}$ and \\ José Alexandre Felizola Diniz-Filho²
}

\begin{abstract}
${ }^{1}$ Programa de Pós-Graduação em Ecologia e Evolução, ICB, Universidade Federal de Goiás, CP 131, 74001-970 Goiânia, GO, Brazil, ${ }^{2}$ Departamento de Ecologia, ICB, Universidade Federal de Goiás, ${ }^{3}$ Programa CAPES PNPD, Ecologia e Evolução, ICB, Universidade Federal de Goiás
\end{abstract}

\author{
${ }^{\star}$ Correspondence: Ricardo Dobrovolski, \\ Departamento de Ecologia, ICB, Universidade \\ Federal de Goiás (UFG), Cx.P. 131, 74001-970 \\ Goiânia, GO, Brazil. \\ E-mail: rdobrovolski@gmail.com
}

\begin{abstract}
Aim We tested whether the geographic variation in the proportion of beta diversity attributed to nestedness or turnover components was explained by the effect of past glaciation events. Specifically, we tested the hypothesis that most of the beta diversity in regions retaining ice until recent periods was due to nestedness. Additionally, we tested whether the variation was influenced by thermal tolerance and the dispersal ability of species.
\end{abstract}

Location This study analysed data from the New World.

Methods We used presence/absence data for amphibians, birds and mammals of the New World. We calculated beta diversity among each $1^{\circ} \times 1^{\circ}$ cell and the adjacent cells using the Sorensen dissimilarity index that expresses the total beta diversity. Furthermore, we partitioned it into turnover and nestedness components. The relative importance of the two latter components was expressed as the proportion of total beta diversity explained by nestedness $\left(\beta_{\text {ratio }}\right)$. We calculated the correlation between $\beta_{\text {ratio }}$ and the time each cell was free of ice since the last glaciation (cell age). To control the effects of spatial autocorrelation, we calculated geographically effective degrees of freedom.

Results The proportion of beta diversity attributed to nestedness was negatively correlated with cell age. Moreover, this effect was stronger for amphibians than mammals, and stronger for mammals than birds.

Main conclusions Our results are in accordance with the hypothesis that the nestedness component of beta diversity is more important in areas affected by glaciations until recent time. The beta diversity in high latitudes is the result of past extinctions and recent recolonization, which result in higher levels of nestedness. This process is more evident for vertebrates with lower dispersal ability and lower temperature tolerance.

\section{Keywords}

Dispersal abilities, glaciation, latitudinal gradients, New World, past climate change, spatial autocorrelation, spatial turnover, temperature tolerance.

\section{INTRODUCTION}

One of the main goals of macroecology is to understand the patterns of biological diversity at broad spatial scale (Gaston \& Blackburn, 2000; Hawkins \& Diniz-Filho, 2008). Biological diversity can be analysed by at least two components: the local component (alpha diversity) and the regional component, or

(C) 2011 Blackwell Publishing Ltd diversity among sites (beta diversity). Although there has been much success in understanding the patterns and processes that explain local species richness at broad scales (e.g. Hawkins, 2001; Hawkins et al., 2003; Terribile et al., 2009), there has been an increasing interest in the factors that drive changes in beta diversity at macroecological scales (e.g. Williams, 1996; Koleff et al., 2003; Veech \& Crist, 2007; Melo et al., 2009). Beta diversity is a 
well-established and widely used concept in ecology and has been measured in different ways and for various purposes (for a review see Tuomisto, 2010a,b).

Although beta diversity has been used synonymously with 'species turnover' (Wilson \& Shmida, 1984; Gaston \& Blackburn, 2000; Gaston et al., 2007; Qian et al., 2009), it has also been recognized (e.g. Harrison et al., 1992) to be composed of distinct components that include both turnover (i.e. changes in species composition among local assemblages) and nestedness (i.e. the loss of species at certain sites results in a pattern in which the biota present there is a subset of species at richer sites). In a recent study, Baselga (2010) proposed a framework to evaluate beta diversity as an overall phenomenon evaluated by the Sorensen $\left(\beta_{\text {sor }}\right)$ index. Baselga (2010) suggested that total beta diversity can be separated into two distinct parts: the species turnover, which is measured by the Simpson dissimilarity index $\left(\beta_{\text {sim }}\right)$, and the nestedness component $\left(\beta_{\text {nes }}\right)$ that was derived by Baselga (2010). Therefore, $\beta_{\text {sor }}=\beta_{\text {sim }}+\beta_{\text {nes. }}$.

These components of beta diversity, however, should not be uniformly distributed in geographical space. It can be expected that in certain areas most of the beta diversity would be composed of species turnover, while in other areas the nestedness should be the principal component. In his original paper, Baselga (2010) proposed that the pattern of beta diversity partitioning found for beetles in Europe is explained by the effect of past glaciations. A specific mechanism was proposed to explain this pattern of beta-diversity partitioning: areas at low latitudes in the present climate suffered less variation in temperature during glaciation cycles, thereby maintaining a high number of species and representing centres of speciation, triggering high endemism (see Jansson, 2003) and allowing higher species turnover. In contrast, regions at high latitudes were severely affected by glaciations that caused extinctions in the past; therefore, beta diversity may be the result of past extinctions and recent recolonization, resulting in a higher relative importance of the nestedness component (Baselga, 2010).

If this mechanism is true, then the effect of past glaciations should not have been the same for different species. The life history of species could have influenced the effects of this process on their current beta-diversity patterns. Two characteristics are expected to be very important in the response to climate change: the ability to regulate body temperature via metabolic heat (endothermy) and dispersal ability. Endothermy makes organisms more resistant to variations in environmental temperatures and, consequently, endotherms are able to survive in environments with lower temperatures (Angilletta, 2009). Ectotherms, in turn, are more sensitive to low energy in the environment (Buckley \& Jetz, 2007). The capacity for dispersal may also influence the ability of organisms to track the optimal environmental conditions after climate change (Harrison et al., 1992). Species with a lower dispersal ability recolonize areas affected by glaciations more slowly (Smith \& Green, 2005). Volant animals are better dispersers than non-volant animals (Harrison et al., 1992; Böhning-Gaese et al., 1998). Consequently, the overall beta diversity, and especially the beta diversity due to nestedness, should be higher in ectotherms and animals with poor dispersal abilities.

The aim of this study was to test the hypothesis that the relative portion of beta diversity due to nestedness is higher in areas where the effects of glaciation were stronger (i.e. the time for which the area remained covered by ice after the Last Glacial Maximum was longer). Additionally, we hypothesized that this effect would be most evident for ectotherms and species with poor dispersal capabilities. We used three different groups of organisms that, in general, differ in their abilities to control internal temperature and in their dispersal abilities: amphibians (ectotherms, non-volant), mammals (endotherms, mostly nonvolant) and birds (volant and endotherms). We predicted that amphibians were extirpated earlier from areas that were subjected to coverage by ice and that their recolonization was slower, resulting in a higher proportion of beta diversity attributed to nestedness. In contrast, due to their better ability to control their own temperature, we expected that birds were able to resist climate change for longer, and because of their better dispersal capacity were able to recolonize earlier after ice melting, thereby generating a richer pool of species in these areas and enabling the existence of beta diversity not only due to nestedness but also due to the turnover of species.

\section{METHODS}

\section{Data}

We used digitized bird (Ridgely et al., 2005), mammal (Patterson et al., 2005) and amphibian (Stuart et al., 2004) datasets for 3836 bird, 1641 mammals and 1303 amphibian species (available at http://www.natureserve.org). These databases were processed using ESRI ARCVIEW 3.1 to record a species' presence, as defined by its breeding range, in a $42001^{\circ}$ by $1^{\circ}$ cell grid covering the New World. Each species' presence was recorded when its range polygon covered $>50 \%$ of the cell area. Small islands and cells with $<50 \%$ of land area were excluded from the grid. The resulting presence/absence matrices for the New World were used to calculate beta diversity by different metrics.

To test the effect of ice ages on beta diversity partition, we used cell age data. This was estimated by changes in ice coverage at 1-kyr intervals since the Last Glacial Maximum (see Peltier, 1993; data available at ftp://ftp.ncdc.noaa.gov/pub/data/paleo/ ice_topo). For those cells that remained non-glaciated during this period, we assigned an age of 22,000 years (see Hawkins \& Porter, 2003).

\section{Measuring beta diversity}

Following Baselga (2010), we calculated three measures of beta diversity, the Sorensen dissimilarity index $\left(\beta_{\mathrm{sor}}\right)$, the Simpson dissimilarity index $\left(\beta_{\text {sim }}\right)$ and the nestedness index $\left(\beta_{\text {nes }}\right)$, by a routine that we wrote in $\mathrm{R}$ ( $\mathrm{R}$ Development Core Team, 2009). The total beta diversity is represented by $\beta_{\text {sor }}$, where $\beta_{\text {sim }}$ is the species turnover part of beta diversity and $\beta_{\text {nes }}$ is the nestedness component of beta diversity. The formulae that we used are as follows: 


\section{Birds}

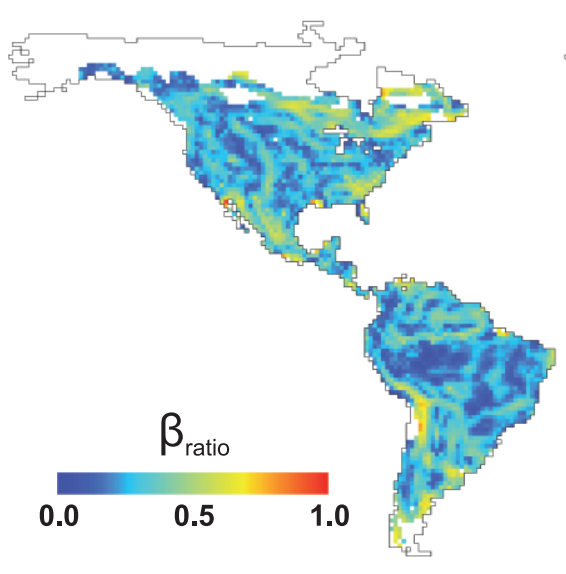

Mammals

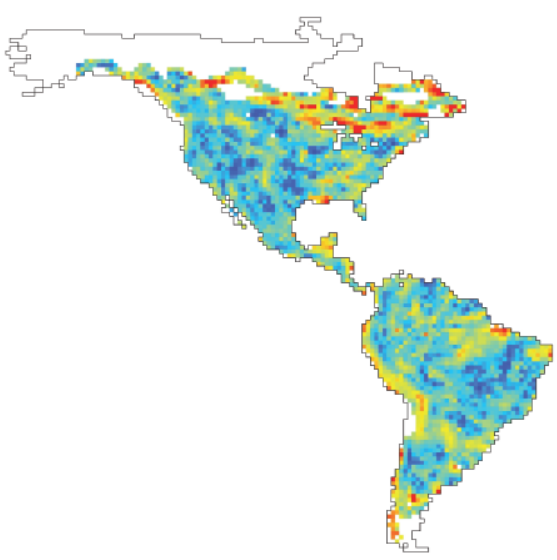

Amphibians

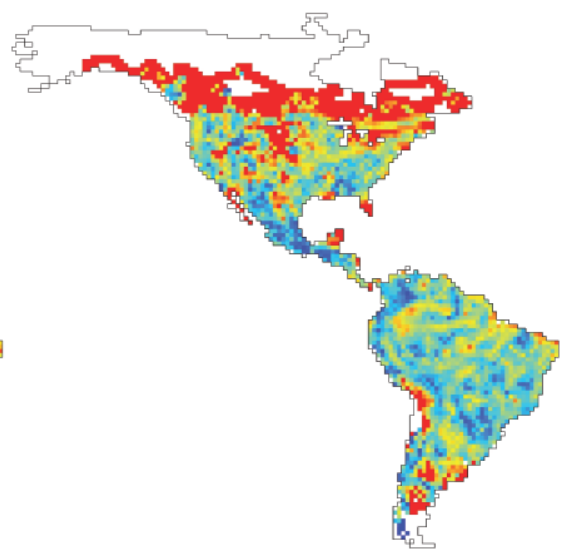

Figure 1 Beta diversity in the New World. The $\beta_{\text {ratio }}$ index (i.e. the proportion of total beta diversity explained by nestedness) was calculated among each $1^{\circ} \times 1^{\circ}$ cell and all of its adjacent cells for birds, mammals and amphibians.

$$
\begin{aligned}
\beta_{\text {sor }}= & b+c /(2 a+b+c) \\
\beta_{\text {sim }}= & \min (b, c) /[a+\min (b, c)] \\
\beta_{\text {nes }}= & \{[\max (b, c)-\min (b, c)] /[2 a+\min (b, c)+\max (b, c)]\} \\
& \times\{a /[a+\min (b, c)]\}
\end{aligned}
$$

where $a$ is the number of species in both cells, $b$ is the number of species exclusive to the focal cell and $c$ is the number of species exclusive to the adjacent cell. It is important to highlight that dissimilarity due to nestedness $\left(\beta_{\text {nes }}\right)$ is related to, but different from, nestedness per se (Baselga, 2010). For example, nestedness has been measured by the nestedness metric based on overlap and decreasing fill (NODF) (Almeida-Neto et al., 2008).

Beta-diversity components attributed to each cell represented the mean values between the focal cell and each of the eight adjacent cells. However, fewer values were used for coastal cells (see Melo et al., 2009). Next, we obtained the ratio between $\beta_{\text {nes }}$ and $\beta_{\text {sor }}$ for each cell (hereafter ' $\beta_{\text {ratio }}$ '). Thus, values smaller than 0.5 indicated that beta diversity was determined mainly by species turnover, whereas values greater than 0.5 indicated that nestedness was the most important component. Cells were eliminated from the analysis in the following cases: (1) discrepant values of $\beta_{\text {nes }}$ in coastal cells that were most likely related to errors in the limits of the species distribution polygons; (2) cells with no species; and (3) cells where $\beta_{\text {sor }}=0$. The final dataset included 3232 cells.

\section{Statistical analyses}

We evaluated the distribution and spatial structure of $\beta_{\text {ratio }}$ for the three groups of organisms by comparing their respective correlograms, i.e. the plot of the Moran's I in different classes of distances (Legendre \& Legendre, 1998; Diniz-Filho et al., 2003). To calculate the correlograms, we used 22 classes of distance determined by the criterion of an equal number of pairs to compute Moran's $I$.

We evaluated the effects of ice age on $\beta_{\text {ratio }}$ (and on the other components of beta diversity, $\beta_{\text {sor }}, \beta_{\text {sim }}$ and $\beta_{\text {nes }}$ ) separately by simple linear correlation analyses. To avoid the overestimation of degrees of freedom due to spatial autocorrelation, we used the method from Clifford et al. (1989) to calculate geographically effective degrees of freedom. Thus, we obtained unbiased estimates of Type I errors for the correlations. All spatial analyses were performed using Spatial Analysis in Macroecology software (sAm, v.4.0; Rangel et al., 2006, 2010; freely available at http:// www.ecoevol.ufg.br/sam).

\section{RESULTS}

The proportion of the nestedness component in the overall beta diversity $\left(\beta_{\text {ratio }}\right)$ was higher for amphibians (mean \pm SD $=0.527$ $\pm 0.278)$ than mammals $(0.426 \pm 0.187)$ and birds $(0.302 \pm$ 0.135 ) (Figs $1 \& 2$ ). The distribution of $\beta_{\text {ratio }}$ also varies among taxonomic groups. Skewness was highest for mammals (0.787), and was followed by birds (0.681). The distribution of values of $\beta_{\text {ratio }}$ tended to be closer to normal for amphibians (0.329) (Fig. 2). Geographically, the peaks of $\beta_{\text {ratio }}$ for amphibians and mammals were found at high latitudes (Fig. 1).

Although we focused on $\beta_{\text {ratio }}$ in this study, we also mapped the separate components of beta diversity for birds, mammals and amphibians (see Appendix S1 in Supporting Information). Total beta diversity $\left(\beta_{\text {sor }}\right)$ was higher for amphibians and similar for birds and mammals. Higher values were concentrated in mountainous areas. The nestedness component $\left(\beta_{\text {nes }}\right)$ for amphibians was greater both in mountainous areas and at higher latitudes. The absolute values of $\beta_{\text {sim }}$ were higher than $\beta_{\text {nes }}$, but the magnitude of this difference was higher for birds than mammals and amphibians.

We found negative relationships between cell age and $\beta_{\text {ratio }}$ that were stronger for amphibians $(r=-0.413, P=0.005)$ than mammals $(r=-0.342, P=0.001)$ and birds $(r=-0.179$, 

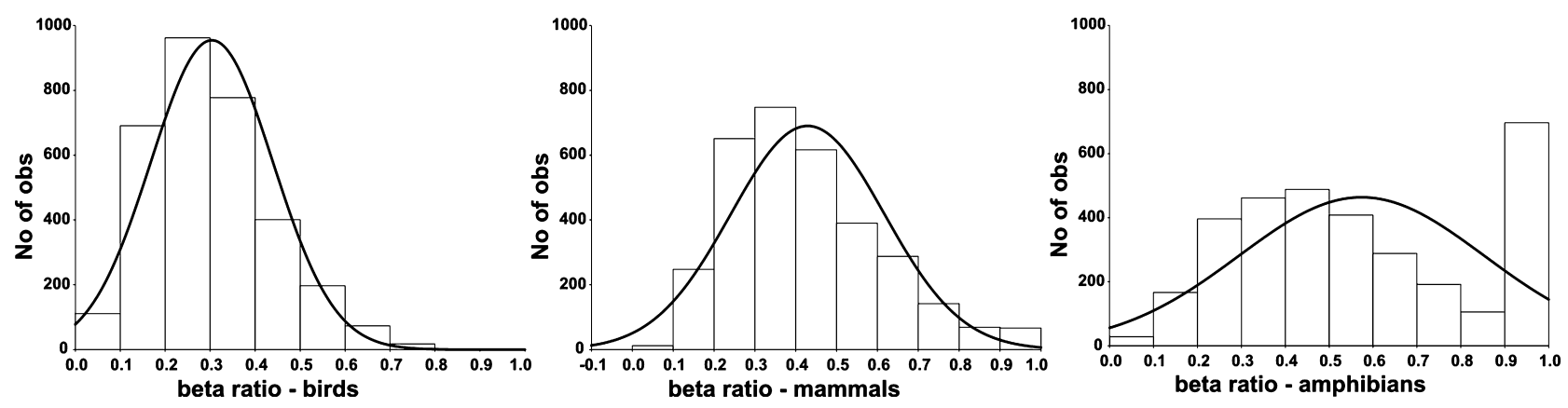

Figure 2 Histograms of $\beta_{\text {ratio }}$ for birds, mammals and amphibians of the New World. $\beta_{\text {ratio }}$ is the proportion of total beta diversity explained by nestedness.

Table 1 Correlation of $\beta_{\text {ratio }}$ for birds, mammals and amphibians of the New World with cell age (the time each cell was free of ice since last glaciation).

\section{Cell age}

\begin{tabular}{llrl}
\hline Group & \multicolumn{1}{l}{$r$} & d.f. & $P$ \\
\hline Birds & -0.179 & 127.0 & 0.043 \\
Mammals & -0.342 & 99.9 & 0.001 \\
Amphibians & -0.413 & 17.4 & 0.005 \\
\hline
\end{tabular}

The degrees of freedom were corrected using the method proposed by Clifford et al. (1989). Pearson's $r(r)$; degrees of freedom (d.f.) and probability value $(P)$.

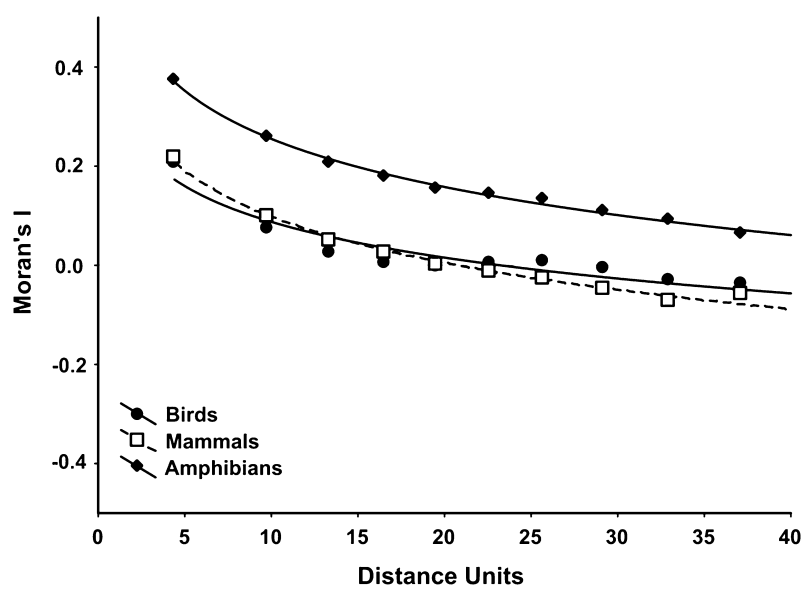

Figure 3 Spatial correlograms based on Moran's I autocorrelation coefficients for $\beta_{\text {ratio }}$ for birds, mammals and amphibians of the New World. Distance units are degrees. $\beta_{\text {ratio }}$ is the proportion of total beta diversity explained by nestedness.

$P=0.043$ ) (Table 1). The spatial structure was more evident for amphibians than mammals and birds, as shown by their spatial correlograms (Fig. 3) and by the reduction in degrees of freedom (Clifford et al., 1989). The turnover component had a positive relationship with cell age for mammals $(r=0.390$, $P=0.022)$ and amphibians $(r=0.0331, P=0.031)$ (see Appendix S2).

\section{DISCUSSION}

Previous studies have shown beta-diversity patterns for amphibians, mammals and birds (McKnight et al., 2007; Buckley \& Jetz, 2008; Melo et al., 2009; Qian, 2009b) and have attempted to correlate those patterns with current environmental predictors (e.g. Gaston et al., 2007; Buckley \& Jetz, 2008; Melo et al., 2009; Qian et al., 2009). Here, we show the geographic distribution of the different components of beta diversity for these groups in New World. Although we did not perform a formal evaluation, the concentration of higher values of the separate components of beta diversity $\left(\beta_{\text {sor }}, \beta_{\text {sim }}\right.$ and $\left.\beta_{\text {nes }}\right)$ in mountainous areas probably reflects the importance of altitude range (e.g. Melo et al., 2009) and geographic distribution of mean range sizes (Graves \& Rahbek, 2005; Hawkins \& Diniz-Filho, 2006).

The focus of our work was to show the spatial pattern of the relative importance of nestedness and turnover components of beta diversity in the New World. This variation was highly dependent on the group of organisms analysed and can be explained by the time that the regions were free of ice cover since the last glaciation, in accordance with the hypothesis of Baselga (2010). In relation to his original paper on betadiversity partitioning, we were able to advance the following aspects. Baselga (2010) evaluated the beta diversity of beetles based on national inventories and compared southern and northern European countries. Additionally, Baselga (2010) evaluated the two components of beta diversity (turnover and nestedness) separately. Here, we combined both components in an index $\left(\beta_{\text {ratio }}\right)$ that expressed the relative importance of each component. We evaluated this partition for three groups of vertebrates (amphibians, mammals and birds) of the New World, which generally have different dispersal abilities. This allowed us to test the proposed mechanisms underlying the geographic patterns in beta diversity. Additionally, Baselga's (2010) ad hoc explanation of the partition of beta diversity among northern and southern European countries was based on the effect of past glaciations. Therefore, we used an explicit variable that reflected the time that each cell was free of ice since the last glaciation (cell age). This variable enabled us to formally test the hypothesis of Baselga (2010).

As our results suggest, the higher prevalence of the nestedness component of beta diversity is the result of the extinction and 
slow recolonization of species in areas covered by ice in the last glaciations. In areas not covered by ice, the extinction events should have been milder, maintaining a greater number of species and allowing the emergence of endemism (Jansson, 2003) and the eventual turnover of species. Our predictor variable of cell age reflected an extreme climate change caused by glaciations. Glaciations probably caused great rates of extinction where they occurred. However, after the ice melted, some species were able recolonize the cells that were free of ice. The higher cell ages allowed more time for recolonization. This mechanism explains why we found higher levels of the nestedness component in areas where the effect of glaciation was higher (i.e. lower cell age). The species present in areas that were covered by ice during the last glaciations were subsets of species that remained in the areas free of ice.

The effect of this relatively recent environmental change (glaciations) was found to be important in the determination of the diversity (alpha and beta) patterns for several groups (Hawkins \& Porter, 2003; Jansson, 2003; Araújo et al., 2008; Baselga, 2008; Davies et al., 2009). This environmental change also was responsible for driving geographical patterns in species traits, such as body size (Diniz-Filho et al., 2009). However, the effect of glaciation cycles on the patterns of beta-diversity partitions that our work supports does not exclude the role that other processes could play in explaining the patterns of diversity. These other processes could have acted over evolutionary time, and could have included niche conservatism (Wiens \& Donoghue, 2004), climate changes over a longer time-scale (Hawkins et al., 2006), the effect of time and area or differences in the diversification rates (Mittelbach et al., 2007). Nevertheless, the spatial patterns in $\beta_{\text {ratio }}$ and the variation among birds, mammals and amphibians suggest that a simpler process, acting over a shorter timescale (approximately 20,000 yr вр), may be responsible for most of the beta-diversity patterns that we currently see, despite these more complex processes acting over much broader time-scales.

Dispersal ability has an important effect on diversity patterns. Its effects have been shown for alpha diversity (Hillebrand, 2004) and also for beta diversity (Qian, 2009a,b; JiménezValverde et al., 2010). Here, we demonstrated the effect of dispersal ability on beta-diversity partitions and showed that this trait interacts with past climate dynamics to create current patterns of species turnover and nestedness. As expected, the resulting pattern was not the same for different groups of organisms. Birds can fly and are endotherms. Consequently, they were able to recolonize the ice-free areas quickly and with more species, thereby generating beta diversity by nestedness and turnover. In contrast, amphibians have poor dispersal abilities (Smith \& Green, 2005; Buckley \& Jetz, 2007) and are ectotherms. Therefore, they are more prone to extinction in the areas covered by ice and the recolonization process is more difficult for them. Consequently, the nestedness patterns for amphibians were stronger than for the other groups analysed. Mammals are endotherms and better dispersers than amphibians, but are worse dispersers than birds (Böhning-Gaese et al., 1998). Consequently, their pattern of beta-diversity partition was, as expected, between that of birds and amphibians. The difference among the three groups of vertebrates was also expressed by the difference in the spatial structure of the data. The higher spatial autocorrelation for amphibians is consistent with the more limited dispersal abilities of species in this group (making surrounding areas more similar).

Our work applied Baselga's (2010) beta-diversity partition in order to test the hypothesis of the effect of glaciations on the current patterns of beta diversity. Our analyses provide insights into how the beta-diversity partition method can contribute to a better understanding of the mechanisms underlying the community assemblage patterns of beta diversity at the macroecological scale in response to environmental change. Moreover, our results reveal that these changes may be different for various organisms in accordance with their traits, such as their dispersal abilities.

\section{ACKNOWLEDGEMENTS}

We thank Jack Lennon and two anonymous referees whose comments helped improve the manuscript. Work by R.D. was supported by a CNPq doctoral fellowship. F.A.S.C. is supported by a CAPES post-doctoral fellowship. A.S.M was supported by a research fellowship (302482/2008-3) and research grants (474560/2009-0; 558187/2009-9) from CNPq. J.A.F.D.F. was supported by several CNPq and FUNAPE/UFG grants.

\section{REFERENCES}

Almeida-Neto, M., Guimarães, P., Guimarães, P.R., Loyola, R.D. \& Ulrich, W. (2008) A consistent metric for nestedness analysis in ecological systems: reconciling concept and measurement. Oikos, 117, 1227-1239.

Angilletta, M.J., Jr (2009) Thermal adaptation: a theoretical and empirical synthesis. Oxford University Press, Oxford.

Araújo, M.B., Nogués-Bravo, D., Diniz-Filho, J.A.F., Haywood, A.M., Valdes, P.J. \& Rahbek, C. (2008) Quaternary climate changes explain diversity among reptiles and amphibians. Ecography, 31, 8-15.

Baselga, A. (2008) Determinants of species richness, endemism and turnover in European longhorn beetles. Ecography, 31, 263-271.

Baselga, A. (2010) Partitioning the turnover and nestedness components of beta diversity. Global Ecology and Biogeography, 19, 134-143.

Böhning-Gaese, K., González-Guzmán, L.I. \& Brown, J.H. (1998) Constraints on dispersal and the evolution of the avifauna of the Northern Hemisphere. Evolutionary Ecology, 12, 767-783.

Buckley, L.B. \& Jetz, W. (2007) Environmental and historical constraints on global patterns of amphibian richness. Proceedings of the Royal Society B: Biological Sciences, 274, 1167-1173.

Buckley, L.B. \& Jetz, W. (2008) Linking global turnover of species and environments. Proceedings of the National Academy of Sciences USA, 105, 17836-17841.

Clifford, P., Richardson, S. \& Hémon, D. (1989) Assessing the significance of the correlation between two spatial processes. Biometrics, 45, 123-134. 
Davies, T.J., Purvis, A. \& Gittleman, J.L. (2009) Quaternary climate change and the geographic ranges of mammals. The American Naturalist, 174, 297-307.

Diniz-Filho, J.A.F., Bini, L.M. \& Hawkins, B. (2003) Spatial autocorrelation and red herrings in geographical ecology. Global Ecology and Biogeography, 12, 53-64.

Diniz-Filho, J.A.F., Rodríguez, M., Bini, L.M., Olalla-Tarraga, M.Á., Cardillo, M., Nabout, J.C., Hortal, J. \& Hawkins, B. (2009) Climate history, human impacts and global body size of Carnivora (Mammalia: Eutheria) at multiple evolutionary scales. Journal of Biogeography, 36, 2222-2236.

Gaston, K.J. \& Blackburn, T.M. (2000) Pattern and process in macroecology. Blackwell Science, Oxford.

Gaston, K.J., Davies, R.G., Orme, C.D.L., Olson, V.A., Thomas, G.H., Ding, T.S., Rasmussen, P.C., Lennon, J.J., Bennett, P.M., Owens, I.P.F. \& Blackburn, T.M. (2007) Spatial turnover in the global avifauna. Proceedings of the Royal Society B: Biological Sciences, 274, 1567-1574.

Graves, G.R. \& Rahbek, C. (2005) Source pool geometry and the assembly of continental avifaunas. Proceedings of the National Academy of Sciences USA, 102, 7871-7876.

Harrison, S., Ross, S.J. \& Lawton, J.H. (1992) Beta diversity on geographic gradients in Britain. Journal of Animal Ecology, 61, 151-158.

Hawkins, B.A. (2001) Ecology's oldest pattern? Trends in Ecology and Evolution, 16, 470.

Hawkins, B.A. \& Diniz-Filho, J.A.F. (2006) Beyond Rapoport's rule: evaluating range size patterns of New World birds in a two-dimensional framework. Global Ecology and Biogeography, 15, 461-469.

Hawkins, B.A. \& Diniz-Filho, J.A.F. (2008) Macroecology. Encyclopedia of life sciences (ELS). John Wiley and Sons, Chichester.

Hawkins, B. \& Porter, E.E. (2003) Relative influences of current and historical factors on mammal and bird diversity patterns in deglaciated North America. Global Ecology and Biogeography, 12, 475-481.

Hawkins, B.A., Porter, E.E. \& Diniz-Filho, J.A.F. (2003) Productivity and history as predictors of the latitudinal diversity gradient of terrestrial birds. Ecology, 84, 1608-1623.

Hawkins, B.A., Diniz-Filho, J.A.F., Jaramillo, C.A. \& Soeller, S.A. (2006) Post-Eocene climate change, niche conservatism, and the latitudinal diversity gradient of New World birds. Journal of Biogeography, 33, 770-780.

Hillebrand, H. (2004) On the generality of the latitudinal diversity gradient. The American Naturalist, 163, 192-211.

Jansson, R. (2003) Global patterns in endemism explained by past climatic change. Proceedings of the Royal Society B: Biological Sciences, 270, 583-590.

Jiménez-Valverde, A., Baselga, A., Melic, A. \& Txasko, N. (2010) Climate and regional beta-diversity gradients in spiders: dispersal capacity has nothing to say? Insect Conservation and Diversity, 3, 51-60.

Koleff, P., Lennon, J.J. \& Gaston, K.J. (2003) Are there latitudinal gradients in species turnover? Global Ecology and Biogeography, 12, 483-498.
Legendre, P. \& Legendre, L. (1998) Numerical ecology, 2nd edn. Elsevier Science, Amsterdam.

McKnight, M.W., White, P.S., McDonald, R.I., Lamoreux, J.F., Sechrest, W., Ridgely, R.S. \& Stuart, S.N. (2007) Putting betadiversity on the map: broad-scale congruence and coincidence in the extremes. PLoS Biology, 5, e272.

Melo, A.S., Rangel, T.F.L.V. \& Diniz-Filho, J.A.F. (2009) Environmental drivers of beta-diversity patterns in New-World birds and mammals. Ecography, 32, 226-236.

Mittelbach, G.G., Schemske, D.W., Cornell, H.V. et al. (2007) Evolution and the latitudinal diversity gradient: speciation, extinction and biogeography. Ecology Letters, 10, 315331.

Patterson, B.D., Ceballos, G., Sechrest, W., Tognelli, M.F., Brooks, T., Luna, L., Ortega, P., Salazar, I. \& Young, B.E. (2005) Digital distribution maps of the mammals of the Western Hemisphere, version 2.0. NatureServe, Arlington, VA. Available at: http://www.natureserve.org/getData/mammalMaps.jsp.

Peltier, W. (1993) Time dependent topography through glacial cycle. IGBP, PAGES/World Data Center-A for Paleoclimatology Data Contribution Series no. 93-015. NOAA/NGDC Paleoclimatology Program, Boulder, CO. Available at: ftp:// ftp.ncdc.noaa.gov/pub/data/paleo/ice_topo (accessed 23 April 2010).

Qian, H. (2009a) Beta diversity in relation to dispersal ability for vascular plants in North America. Global Ecology and Biogeography, 18, 327-332.

Qian, H. (2009b) Global comparisons of beta diversity among mammals, birds, reptiles, and amphibians across spatial scales and taxonomic ranks. Journal of Systematics and Evolution, 47, 509-514.

Qian, H., Badgley, C. \& Fox, D.L. (2009) The latitudinal gradient of beta diversity in relation to climate and topography for mammals in North America. Global Ecology and Biogeography, 18, 111-122.

R Development Core Team (2009) R: a language and environment for statistical computing, ver. 2.10.1. R Foundation for Statistical Computing, Vienna, Austria. Available at: http:// www.r-project.org/ (accessed 12 March 2010).

Rangel, T.F.L.V.B., Diniz-Filho, J.A.F. \& Bini, L.M. (2006) Towards an integrated computational tool for spatial analysis in macroecology and biogeography. Global Ecology and Biogeography, 15, 321-327.

Rangel, T.F.L.V.B., Diniz-Filho, J.A.F. \& Bini, L.M. (2010) SAM: a comprehensive application for spatial analysis in macroecology. Ecography, 33, 46-50.

Ridgely, R.S., Allnutt, T.F., Brooks, T., McNicol, D.K., Mehlman, D.W., Young, B.E. \& Zook, J.R. (2005) Digital distribution maps of the birds of the Western Hemisphere, version 1.0. NatureServe, Arlington, VA. Available at: http://www. natureserve.org/getData/birdMaps.jsp.

Smith, M.A. \& Green, D.M. (2005) Dispersal and the metapopulation paradigm in amphibian ecology and conservation: are all amphibian populations metapopulations? Ecography, 28, 110-128. 
Stuart, S.M., Chanson, J.S., Cox, N.A., Young, B.E., Rodrigues, A.S.L., Fischman, D.L. \& Waller, R.W. (2004) Status and trends of amphibian declines and extinctions worldwide. Science, 306, 1783-1786.

Terribile, L.C., Diniz-Filho, J.A.F., Rodríguez, M.Á. \& Rangel, T.F.L.V.B. (2009) Richness patterns, species distributions and the principle of extreme deconstruction. Global Ecology and Biogeography, 18, 123-136.

Tuomisto, H. (2010a) A diversity of beta diversities: straightening up a concept gone awry. Part 1 . Defining beta diversity as a function of alpha and gamma diversity. Ecography, 33, 2-22.

Tuomisto, H. (2010b) A diversity of beta diversities: straightening up a concept gone awry. Part 2. Quantifying beta diversity and related phenomena. Ecography, 33, 23-45.

Veech, J.A. \& Crist, T.O. (2007) Habitat and climate heterogeneity maintain beta-diversity of birds among landscapes within ecoregions. Global Ecology and Biogeography, 16, 650-656.

Wiens, J.J. \& Donoghue, M.J. (2004) Historical biogeography, ecology and species richness. Trends in Ecology and Evolution, 19, 639-644.

Williams, P.H. (1996) Mapping variations in the strength and breadth of biogeographic transition zones using species turnover. Proceedings of the Royal Society B: Biological Sciences, 263, 579-588.

Wilson, M.V. \& Shmida, A. (1984) Measuring beta diversity with presence-absence data. Journal of Ecology, 72, 1055-1064.

\section{SUPPORTING INFORMATION}

Additional Supporting Information may be found in the online version of this article:
Appendix S1 Beta diversity in the New World. Different components of beta diversity, including total (Sorensen), turnover (Simpson) and nestedness components, were calculated among each focal $1^{\circ} \times 1^{\circ}$ (latitude $\times$ longitude) cell and all of its adjacent cells for birds, mammals and amphibians.

Appendix S2 Correlation of the different components of beta diversity, $\beta_{\text {sor }}, \beta_{\text {sim }}, \beta_{\text {nes }}$, and $\beta_{\text {ratio }}$ for birds, mammals and amphibians of New World with cell age. The degrees of freedom were corrected by the method proposed by Clifford et al. (1989). Pearson's r (r); degrees of freedom (d.f.) and P value (P).

As a service to our authors and readers, this journal provides supporting information supplied by the authors. Such materials are peer-reviewed and may be reorganized for online delivery, but are not copy-edited or typeset. Technical support issues arising from supporting information (other than missing files) should be addressed to the authors.

\section{BIOSKETCH}

Ricardo Dobrovolski is interested in large-scale patterns in ecology, including global diversity gradients, and the mechanisms driving them. He is especially interested in the impact of human activities, such as agriculture, on these patterns.

Editor: Jack Lennon 